\title{
Use of Ribavirin for Hepatitis C Treatment in the Modern Direct-acting Antiviral Era
}

\author{
Poonam Mathur*, Shyamasundaran Kottilil and Eleanor Wilson \\ Division of Clinical Care and Research, Institute of Human Virology, University of Maryland School of Medicine, Baltimore, MD, USA
}

\begin{abstract}
Ribavirin, once a staple of hepatitis $C$ treatment, has significant drawbacks, including treatment-limiting side effects, the requirement for intensive laboratory monitoring, the need for frequent dose adjustments, and teratogenicity. These factors make it difficult to escalate ribavirin-based HCV treatment to most infected patients globally. Most studies have shown comparable response rates between ribavirin-inclusive and ribavirin-sparing regimens in uncomplicated patient populations. However, ribavirin is still used in the management of patients who have failed previous therapy as well as those with decompensated liver disease. In this review, we explore the evidence supporting the use of ribavirin in the current climate of hepatitis $\mathrm{C}$ treatment with oral combination direct-acting antiviral agents.
\end{abstract}

Citation of this article: Mathur P, Kottilil S, Wilson E. Use of ribavirin for hepatitis $C$ treatment in the modern direct-acting antiviral era. J Clin Transl Hepatol 2018;6(4):1-7. doi: 10.14218/JCTH.2018.00007.

\section{Introduction}

Hepatitis C virus (HCV) infection affects 71 million people worldwide $^{1}$ and is a leading cause of death globally. ${ }^{2}$ Prior to the approval of oral combination direct-acting antivirals (DAAs) in 2014, all recommended HCV treatments included pegylated-interferon $\alpha$ (PEG-IFN $\alpha)$ and ribavirin (RBV). In a recent systematic review and meta-analysis on hepatitis $C$ treatment rates, however, it was estimated that only $25 \%$ of patients with chronic HCV infection worldwide were treated with these immune-based therapies. ${ }^{3}$ Treatment rates were likely limited by a number of factors, including the significant rates of side effects, the lack of adequate numbers of specialist providers, the fact that these therapies were contraindicated in patients with decompensated liver disease, and

Keywords: Chronic hepatitis C; Direct-acting antivirals; Ribavirin.

Abbreviations: DAAs, direct-acting antivirals; DCV, daclatasvir; DNA, deoxyribonucleic acid; EBR, elbasvir; FDA, Food and Drug Administration; GT, genotype; GZR, grazoprevir; HCV, hepatitis C virus; HIV, human immunodeficiency virus; LDV, ledipasvir; PEG-IFN $\alpha$, pegylated-interferon $\alpha$; PrO, paritaprevir, ritonavir, ombitasvir; PrOD, paritaprevir, ritonavir, ombitasvir, dasabuvir; RAS, resistanceassociated substitutions; RBV, ribavirin; RNA, ribonucleic acid; SOF, sofosbuvir; SVR, sustained virologic response; VEL, velpatasvir; WHO, World Health Organization.

Received: 25 January 2018; Revised: 4 June 2018; Accepted: 24 June 2018 * Correspondence to: Poonam Mathur, Institute of Human Virology, University of Maryland School of Medicine, 725 W. Lombard St., Baltimore, MD 21201, USA. Tel: +1-443-326-0506, E-mail: pmathur@ihv.umaryland.edu limited efficacy, particularly in patients with HIV/HCV co-infection or those with advanced liver disease.

Now, interferon-sparing combination DAA regimens have dramatically improved the treatment of $\mathrm{HCV}$, with higher treatment efficacy, improved tolerability, and ease of dosing, with the majority of regimens available in once daily oral dosing. ${ }^{4}$ With the first published trials showing comparable response rates to combination DAA-based $\mathrm{HCV}$ treatments when given with and without RBV, it has been suggested that RBV-sparing regimens would improve treatment safety, tolerability, and adherence. ${ }^{5-7}$ However, there are several clinical scenarios and treatment regimens in which the addition of RBV is still recommended. Here, we discuss the data behind the current guidelines regarding the use of RBV in the revolutionary age of DAA-based treatment for HCV.

\section{RBV}

RBV is a synthetic triazole guanosine analog with activity against both DNA and RNA viruses. ${ }^{8,9}$ Suggested mechanisms of RBV include modulation of T helper-1 and -2 lymphocyte imbalance, depletion of cell guanosine triphosphate by inhibiting inosine monophosphate dehydrogenase, inhibiting the viral RNA-dependent RNA polymerase, impairment of translation by preventing the capping of messenger viral RNA, and lethal viral mutagenesis (Fig. 1) ${ }^{8,9}$ Before the introduction of RBV, PEG-IFN $\alpha$ was the only available treatment for $\mathrm{HCV}$, achieving low rates of sustained virologic response (SVR)defined as absence of plasma HCV RNA in blood at 12 or 24 weeks after stopping treatment-of $15-20 \% .^{8}$ The addition of RBV to PEG-IFN $\alpha$ was shown to be superior to the use of PEG-IFN $\alpha$ alone, ${ }^{8,10-13}$ with an increased SVR rate of approximately $30 \%{ }^{8,10}$ among patients who received a regimen with RBV. The combination of PEG-IFN $\alpha$ and RBV also reduced the risk of post-treatment viral relapse. ${ }^{8}$ In a study by McHutchinson et al., ${ }^{8}$ relapse rates were reduced by $38 \%$ in patients who received PEG-IFN $\alpha$ and RBV for 24 weeks and by $22 \%$ in those who received the regimen for 48 weeks. ${ }^{8}$ Due to higher efficacy and decreased rates of relapse compared to PEG-IFN $\alpha$ regimens alone, PEG-IFN $\alpha$ in combination with RBV became the standard of care for hepatitis C treatment in the 1990s and early 2000s.

Although RBV augments the effects of PEG-IFN $\alpha$ in HCV treatment, there are side effects associated with its use that significantly alter patient adherence and tolerance. Hemolytic anemia is the most significant adverse effect, ${ }^{12,14}$ afflicting up to $10 \%$ of patients, ${ }^{15}$ requiring laboratory monitoring of hemoglobin while on treatment, and frequent dose adjustments. Other side effects include pruritis, fatigue, and upper 


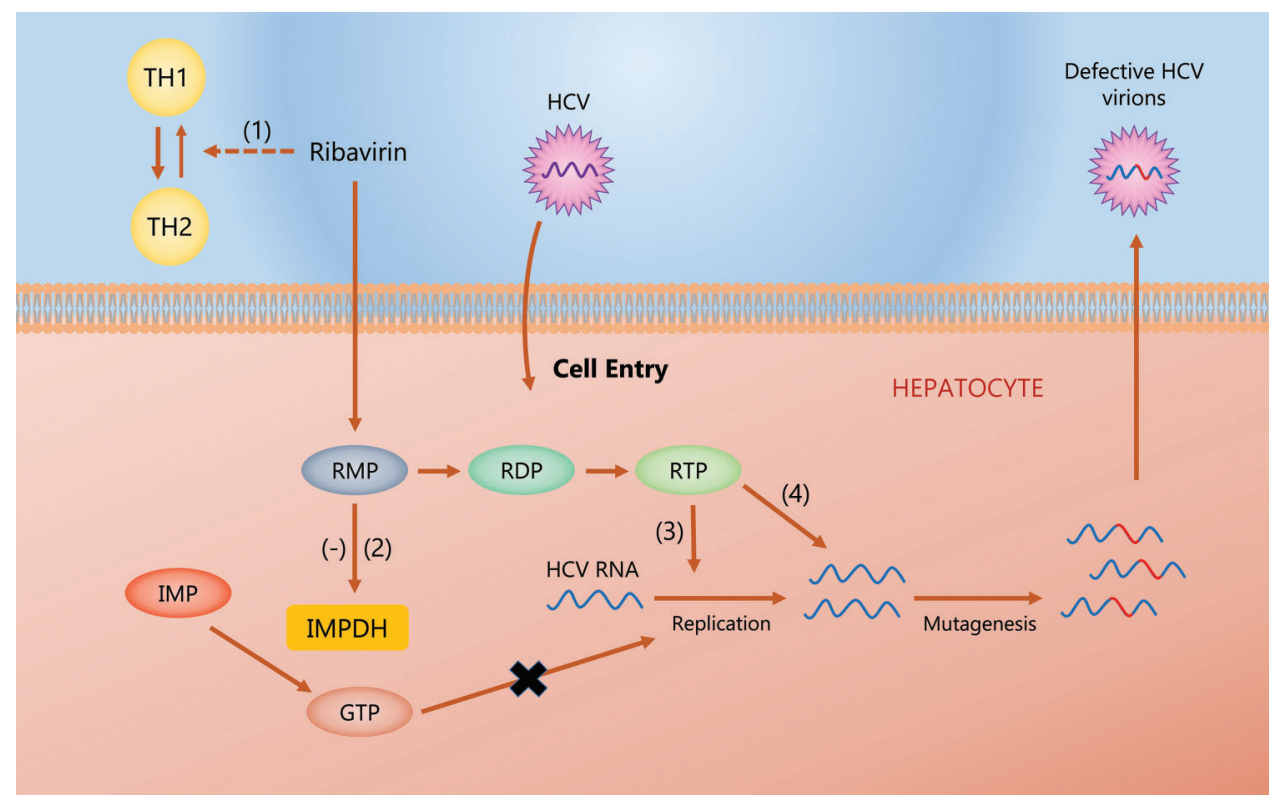

Fig. 1. Proposed mechanisms of RBV. (1) Immunomodulation favoring TH2 over the TH1 phenotype to enhance host immunity to the virus. (2) Competitive inhibition of IMPDH and subsequent depletion of the GTP pool, limiting replication of viral genomes and viral protein synthesis. (3) Inhibition of post-translational mRNA capping by directly inhibiting viral mRNA polymerase. (4) RBV acts as a mutagen in the target virus.

Abbreviations: IMPDH, inosine monophosphate dehydrogenase; RMP, ribavirin monophosphate; RDP, ribavirin diphosphate; RTP, ribavirin triphosphate; TH1, T helper 1; TH2, T helper 2.

respiratory symptoms. ${ }^{14}$ Additionally, RBV is teratogenic, so women of child-bearing age who are on the medication or who have male partners taking the medication must use contraception. ${ }^{16,17}$

\section{DAAs}

In May 2011, the FDA approved the protease inhibitors boceprevir and telaprevir, which were found to increase the rates of SVR 12 weeks after end of treatment $\left(S R_{12}\right)$ when combined with PEG-IFN $\alpha$ and $\mathrm{RBV}_{1}{ }^{18,19}$ and the standard of care for hepatitis $C$ treatment shifted to include one of these oral medications in combination with PEG-IFN $\alpha$ and RBV. Though the protease inhibitors greatly improved HCV treatment, their use was restricted by complicated dosing strategies requiring response-guided therapy and lead-in treatments, a low genetic barrier to resistance, and extensive drug-drug interactions. In 2013, the second generation of DAAs, which included the nucleotide analogue sofosbuvir (SOF), came to the forefront of HCV treatment. When combined with PEG-IFN $\alpha$ and RBV, treatment with SOF produced $\mathrm{SVR}_{12}$ rates in excess of $90 \%{ }^{6,20-22}$ Daclatasvir (DCV), a non-nucleoside RNA polymerase inhibitor, in combination with PEG-IFN $\alpha$ and RBV also demonstrated high antiviral potency. ${ }^{23}$ In light of these near total response rates, investigators began to hypothesize that use of RBV could be eliminated altogether.

Several studies published in 2014 demonstrated that RBVfree treatment regimens, composed of only DAAs, were highly efficacious. The first, by Sulkowski et al. ${ }^{7}$ (AI444040 Study), treated 211 patients with either genotype (GT) 1, 2, or 3 infection with a combination of DCV and SOF with or without RBV for varying treatment durations, including 12 and 24 weeks.
Among the GT1 treatment-naïve patients, a combination of DCV and SOF for 12 weeks produced $\mathrm{SVR}_{12}$ rates of $100 \%$ (41/41), compared to a $95 \%(39 / 41) S^{2} R_{12}$ rate in those patients treated with $\mathrm{DCV}+\mathrm{SOF}+\mathrm{RBV}$ for 12 weeks. Among the GT1 patients who had failed previous treatment with a protease inhibitor, $\mathrm{SVR}_{12}$ rates were $100 \%(21 / 21)$ in patients treated with DCV+SOF for 24 weeks, and 95\% (19/21) for patients treated with DCV+SOF+RBV for 24 weeks. Similarly, among patients with GT2 or GT3 infection, the addition of RBV did not result in a significantly higher virologic response rate; SVR $_{12}$ was $100 \%(14 / 14)$ and $86 \%(12 / 14)$ for patients who were administered the RBV-sparing and RBV-inclusive regimens, respectively. ${ }^{7}$ The lower SVR rates seen with the RBVinclusive regimens may reflect the high potency of DCV and SOF, indicating that RBV does not add to the potency of these oral DAAs.

A second study, LONESTAR, ${ }^{6}$ assessed treatment of GT1 infection in patients who were treatment-naive or previously treated with a protease-inhibitor regimen. There were 19 treatment-naïve patients treated with LDV/SOF for 12 weeks, and $18(95 \%)$ achieved SVR 12 . Among 21 patients who had failed previous treatment with a protease inhibitor, all $(100 \%)$ achieved SVR $_{12}$ after 12 weeks of LDV/SOF+RBV and 18 of 19 (95\%) patients treated with LDV/SOF alone achieved $\mathrm{SVR}_{12}$. In a phase 3 study by Afdhal et al. ${ }^{5}$ (ION-1), 865 treatment-naïve patients with GT1 infection were randomized to receive LDV/SOF for 12 weeks, LDV/SOF+RBV for 12 weeks, LDV/SOF for 24 weeks, or LDV/SOF+RBV for 24 weeks. The rates of $\mathrm{SVR}_{12}$ were $99 \%$ in the group that received 12 weeks of LDV/SOF, $97 \%$ in the group that received 12 weeks of LDV/SOF+RBV, $98 \%$ in the group that received 24 weeks of LDV/SOF, and $99 \%$ in the group that received 24 weeks of LDV/SOF+RBV. 
Last, a phase $2 \mathrm{~b}$ study ${ }^{24}$ evaluated the efficacy of a NS3/4A protease inhibitor (ABT-450) boosted with ritonavir (ABT-450/r), a non-nucleoside polymerase inhibitor (ABT-333), and a NS5A inhibitor (ABT-267) in various combinations with or without RBV. A total of 571 non-cirrhotic patients with GT1 infection (438 treatment-naive and 133 treatmentexperienced) underwent randomization to receive a regimen of ABT-450/r, combined with ABT-267 and/or ABT-333, for 8, 12 or 24 weeks and received at least one dose of therapy. All the subgroups but one also received RBV (dose determined according to body weight). When comparing the $S R_{12}$ rate of the group that received all three drugs without RBV for 12 weeks and the group that received all three drugs with RBV for 12 weeks ( $89 \%$ vs. 96\%, respectively), the contribution of RBV was not significant $(p=0.09)$. These studies suggest that adding RBV to DAAs does not result in significantly higher $S R_{12}$ rates, and are summarized in Table 1.

Studies directly comparing DAAs are lacking, but a recent meta-analysis ${ }^{25}$ comparing different DAA-based regimens, with and without RBV, showed no improvement in treatment efficacy among DAA regimens that included RBV over those that were RBV-sparing. In addition, treatment regimens that incorporated RBV had a higher relative risk of adverse events, including anemia and fatigue. These studies support limiting the use of RBV, given the lack of increase in efficacy and more frequent toxicity. However, as we explore below, there are scenarios in which the addition of RBV to a DAA-based regimen might be warranted.

\section{Roles of RBV}

There are several scenarios and patient groups in which the use of RBV is necessitated, as outlined below and summarized in Table 2.

\section{Augmenting viral response in GT1 patients}

RBV has been efficacious when used in regimens for both treatment-naïve and treatment-experienced patients with GT1 infection. The daily fixed-dose combination of paritaprevir, ritonavir, ombitasvir, and dasabuvir (PrOD), for example, is an alternative regimen approved for treatment-naïve GT1a and $1 \mathrm{~b}$ patients with or without cirrhosis when given with weight-based RBV. The efficacy of RBV when added to PrOD for HCV treatment, especially in GT1a patients, was demonstrated in three trials. In the SAPPHIRE-I trial, ${ }^{26} 631$ treatment-naïve, non-cirrhotic patients with GT1 infection were treated with PrOD+weight-based RBV for 12 weeks. Rates of response were more than $95 \%$ among the treatment-naïve patients with GT1 infection. Additionally, in the PEARL-IV study, Ferenci et al. ${ }^{27}$ evaluated the efficacy of patients treated with PrOD with or without RBV. While there was no difference in rates of virologic failure with or without RBV among the GT1b patients, among the GT1a patients the rate of virologic failure was higher in the RBV-free group compared to the RBV group (7.8\% vs. $2.0 \%$ ). Last, for patients who had previously been unsuccessfully treated with PEG-IFN $\alpha$ and RBV, the SAPPHIRE-2 study ${ }^{28}$ examined the use of PrOD with weight-based RBV in non-cirrhotic GT1 patients. In that study, patients were treated for 12 weeks and had an overall SVR 12 rate of $96 \%$, with no differences noted when comparing response rates between subtypes.

RBV is also used to augment the SVR rate in patients who have baseline HCV resistance, when added to the fixed-dose combination of elbasvir (EBR) and grazoprevir (GZR). In the phase 3 C-EDGE trial, ${ }^{29}$ an international multicenter study, a 12- or 16-week course of EBR/GZR was given to treatmentnaïve patients infected with HCV genotypes 1,4 or 6 , some of whom had compensated cirrhosis. Of the 421 patients, $382(91 \%)$ had GT1 infection. The SVR 12 was $92 \%$ in GT1a patients and $99 \%$ in GT1b patients. However, a post-hoc subanalysis revealed that the presence of baseline NS5A resistance-associated substitutions (RASs) was significantly associated with a decreased virologic response among GT1a patients; of 154 GT1a patients, 19 (12\%) had baseline NS5A RASs, and of these 19, only 11 (58\%) achieved $\mathrm{SVR}_{12}$ compared to $133 / 135$ (99\%) patients without NS5A RASs.

Kwo et al. ${ }^{30}$ extrapolated data from the C-EDGE trial and found that among 58 patients who received EBR/GZR for 16 weeks with RBV, there were no virologic failures. Based on these analyses which suggest that prolonging treatment

Table 1. HCV treatment studies and comparison of SVR rates of RBV-containing regimens

\begin{tabular}{|c|c|c|}
\hline Study & Regimen & SVR Rate \\
\hline Lawitz et al. ${ }^{50}$ & SOF+PEG-IFN $\alpha+$ RBV vs. Placebo+PEG-IFN $\alpha+R B V$ & $91 \%$ vs. $58 \%$ \\
\hline Jacobson et al. ${ }^{51}$ & SOF+RBV for 12 weeks vs. placebo & $78 \%$ vs. $0 \%$ \\
\hline ATOMIC $^{52}$ & $\begin{array}{l}\text { SOF+PEG-IFN } \alpha+R B V \text { for } 12 \text { weeks vs. SOF+PEG-IFN } \alpha+R B V \text { for } \\
24 \text { weeks }\end{array}$ & $90 \%$ vs. $93 \%$ \\
\hline Osinusi et al. ${ }^{53}$ & SOF+weight-based RBV vs. SOF+low-dose RBV & $68 \%$ vs. $48 \%$ \\
\hline Pol et al. ${ }^{23}$ & PEG-IFN $\alpha+$ RBV vs. DCV+PEG-IFN $\alpha+R B V$ & $25 \%$ vs. $83 \%$ \\
\hline \multirow{2}{*}{$\begin{array}{l}\text { Sulkowski et al. } \\
(\text { AI444040) }\end{array}$} & $\mathrm{DCV}+\mathrm{SOF}$ for 12 weeks vs. DCV+SOF+RBV for 12 weeks & $100 \%$ vs. $95 \%$ \\
\hline & $\mathrm{DCV}+\mathrm{SOF}$ for 24 weeks vs. DCV+SOF+RBV for 24 weeks & $100 \%$ vs. $95 \%$ \\
\hline LONESTAR $^{6}$ & LDV+SOF for 12 weeks vs. LDV+SOF+RBV for 12 weeks & $95 \%$ vs. $100 \%$ \\
\hline \multirow[t]{2}{*}{ ION-1 $1^{5}$} & LDV+SOF for 12 weeks vs. LDV+SOF+RBV for 12 weeks & $99 \%$ vs. $97 \%$ \\
\hline & LDV+SOF for 12 weeks vs. LDV+SOF+RBV for 12 weeks & $98 \%$ vs. $99 \%$ \\
\hline Kowdley et al. ${ }^{24}$ & $\begin{array}{l}\text { ABT- } 450 / r+A B T-333+A B T-267 \text { for } 12 \text { weeks vs. ABT- } 450 / r+A B T-333 \\
+ \text { ABT-267+RBV for } 12 \text { weeks }\end{array}$ & $89 \%$ vs. $96 \%$ \\
\hline
\end{tabular}


Mathur P. et al: Role of ribavirin for HCV treatment

Table 2. Indications/clinical scenarios and supporting studies which warrant use of ribavirin

\begin{tabular}{|c|c|c|}
\hline Patient Population & Regimen & Study \\
\hline GT1a and GT1b, non-cirrhotic, treatment-naïve & PrOD+RBV for 12 weeks & SAPPHIRE-I ${ }^{26}$ \\
\hline GT1a, non-cirrhotic, treatment-naïve & PrOD+RBV for 12 weeks & PEARL-IV ${ }^{27}$ \\
\hline GT1, non-cirrhotic, treatment-experienced & PrOD+RBV for 12 weeks & SAPPHIRE- $2^{28}$ \\
\hline $\begin{array}{l}\text { GT1a, with or without compensated cirrhosis, } \\
\text { treatment-naïve or treatment-experienced with } \\
\text { protease inhibitor, with baseline NS5A RASs }\end{array}$ & $E B R / G Z R+R B V$ for 16 weeks & $\begin{array}{l}\text { C-EDGE } \\
\text { C-SALVAG and } \\
\text { C-S1 }\end{array}$ \\
\hline $\begin{array}{l}\text { GT1, compensated cirrhosis, treatment-experienced } \\
\text { with interferon }\end{array}$ & LDV/SOF+RBV for 12 weeks & SIRIUS $^{32}$ \\
\hline $\begin{array}{l}\text { GT3, compensated cirrhosis, treatment-experienced } \\
\text { with interferon }\end{array}$ & SOF/VEL+RBV for 12 weeks & Pianko et al. ${ }^{33}$ \\
\hline $\begin{array}{l}\text { GT4, non-cirrhotic, treatment-naïve and treatment- } \\
\text { experienced }\end{array}$ & PrO+RBV for 12 weeks & PEARL-I ${ }^{34}$ \\
\hline $\begin{array}{l}\text { All genotypes, decompensated cirrhosis, treatment- } \\
\text { naïve and treatment-experienced (except with NS5A } \\
\text { or NS5B inhibitor) }\end{array}$ & SOF/VEL+RBV for 12 weeks & ASTRAL $-4^{35}$ \\
\hline $\begin{array}{l}\text { Post-liver transplant GT 1, 4, 5, } 6 \text { (including } \\
\text { decompensated cirrhosis) }\end{array}$ & LDV/SOF+RBV for 12 weeks & $\begin{array}{l}\text { SOLAR- } 1,{ }^{36} \mathrm{HCV}-\mathrm{TARGET},{ }^{37} \\
\text { and Kwok et al. }\end{array}$ \\
\hline $\begin{array}{l}\text { Post-liver transplant GT 2, } 3 \text { (compensated cirrhosis } \\
\text { only) }\end{array}$ & $\mathrm{DCV} / \mathrm{SOF}+\mathrm{RBV}$ for 12 weeks & ALLY-1, ${ }^{39}$ and Fontana et al. ${ }^{40}$ \\
\hline
\end{tabular}

and adding RBV can overcome reduced EBR susceptibility, NS5A resistance testing is recommended for any GT1a patient in whom EBR/GZR therapy is considered. Use of RBV for the presence of baseline RASs is also recommended for treatment-experienced patients with GT1 infection (with or without cirrhosis), based on the phase 2 C-SALVAGE study. ${ }^{31}$ In this study, 79 patients, 66 of whom (84\%) had previously been treated with a regimen containing a protease-inhibitor, were given 12 weeks of EBR/GZR and weight-based RBV. At entry, 34 patients (43\%) harbored NS3A RASs, identified by population sequencing. Response rates were high, with $76 / 79$ (96.2\%) achieving SVR 12 , including 63/66 (95.5\%) in patients with prior virologic failure, $31 / 34(91.2 \%)$ in patients with baseline NS3 RASs, and 32/34 (94.1\%) in cirrhotic patients. The presence of NS5A or dual NS3/NS5A RASs was associated with lower $\mathrm{SVR}_{12}$ rates ( $75 \%$ and $66 \%$, respectively), but since only 3 patients had virologic failure, firm conclusions could not be drawn. The findings from the C-EDGE and C-SALVAGE trial led to the recommendation that RBV should be added to the combination of EBR/GZR and treatment should be extended to 16 weeks in GT1a patients with or without cirrhosis, if baseline RASs are detected (i.e. substitutions at amino acid positions $28,30,31$ or 93$)$.

Also, in GT1 patients with cirrhosis who are treatmentexperienced with PEG-IFN $\alpha$ and RBV regimens, the addition of RBV can reduce the duration of retreatment when using LDV/SOF. The phase 2 SIRIUS trial ${ }^{32}$ compared 24 weeks of LDV/ SOF with 12 weeks of LDV/SOF+RBV in treatment-experienced patients with GT1 and compensated cirrhosis. Both regimens had similar SVR 12 rates, with $96 \%$ in the LDV/SOF+RBV group and $97 \%$ in the LDV/SOF alone group. This study's findings increased options for GT1 treatment-experienced patients with cirrhosis by providing a regimen option with a shorter duration.

\section{Augmenting response in treatment-experienced GT3 infection}

In GT3 treatment-experienced patients, RBV is an important component of all currently recommended retreatment regimens. In a study by Planko et al., ${ }^{33} 96 \%(n=26)$ of GT3 patients with compensated cirrhosis who were PEG-IFN $\alpha$ and RBV-experienced were successfully retreated with a 12-week duration of SOF/velpatasvir (VEL)+weight-based RBV, as compared to only $88 \%$ of those who received SOF/VEL alone $(n=26)$.

\section{Treatment of GT4 infection}

PEARL-I was a randomized, open label trial that evaluated the efficacy of paritaprevir, ombitasvir, and ritonavir (PrO) with or without RBV in treatment-naïve and treatment-experienced non-cirrhotic patients with GT4 infection. ${ }^{34}$ In 86 treatmentnaïve patients, $S R_{12}$ rates were $100 \%(42 / 42)$ for the RBV-containing regimen and $90.9 \%(40 / 44)$ for the RBV-free regimen. There were 49 treatment-experienced patients who received the $R B V$-containing regimen, and all achieved $S V R_{12}$. The PEARL-I trial demonstrated the efficacy of RBV for virologic cure in treatment-naïve and treatment-experienced GT4 patients.

\section{Patients with decompensated cirrhosis}

The ASTRAL $-4^{35}$ study was the first to compare the use of DAAs both with and without RBV in patients with decompensated cirrhosis and demonstrated the utility of RBV in achieving high $\mathrm{SVR}_{12}$ rates when combined with 12 weeks of SOF/VEL. Regardless of genotype, rates of viral response exceeded $85 \%$ when SOF/VEL was combined with RBV; this combination also resulted in the lowest rates of virologic failure for patients with GT3 (other studies have shown that $\mathrm{SVR}_{12}$ 
rates with GT3 are lower than rates for other genotypes). ${ }^{35}$ The SOF/VEL+RBV regimen was compared to SOF/VEL alone, each for 12 weeks, and SOF/VEL for 24 weeks. The response rate in the 12-week SOV/VEL+RBV arm was $94 \%$, compared to $83 \%$ in SOF/VEL alone for 12 weeks and $86 \%$ in the SOF/VEL 24-week arm. Out of 267 patients treated in that study, 72 had pre-treatment NS5A RASs. Among these 72 patients, $64(89 \%)$ had $\mathrm{SVR}_{12}$ compared to 169 of 183 patients $(92 \%)$ who did not have pre-treatment NS5A RASs. In the SOF/VEL 24-week arm, the presence of NS5A RASs affected virologic cure, as the $\mathrm{SVR}_{12}$ among those with pretreatment NS5A RASs was $90 \%$, compared to a $98 \%$ SVR $_{12}$ rate for those who had no pre-existing NS5A RASs. In addition, among the patients with GT1 who received SOF/VEL + RBV, the SVR 12 rate was $100 \%$ for those who had NS5A RASs and $98 \%$ for those who did not, demonstrating that $\mathrm{RBV}$ is an important adjunct to increase the rate of virologic cure with a 12-week regimen in patients with baseline resistance. Based on the ASTRAL- 4 study, the benefits of RBV in patients with decompensated cirrhosis include augmenting viral response, increasing the potency of HCV regimens in order to shorten treatment duration, and serving as a salvage treatment option for those patients in whom HCV treatment is of top priority in order to decrease risk of hepatocellular carcinoma and overall mortality.

\section{Patients with liver transplants}

For patients who are post-liver transplantation (with or without $\mathrm{HCV}$ treatment experience and/or compensated or decompensated cirrhosis) and infected with HCV 1, 4, 5 or 6, the only recommended, evidence-based regimen for treatment which includes RBV is in combination with LDV/SOF for 12 weeks. The evidence for use of RBV with LDV/SOF is provided by three studies. The SOLAR- $1^{36}$ study was a USAbased, phase 2, open-label study assessing LDV/SOF+RBV in patients with GT1 or 4 infection in two cohorts, one of which included patients who were post-liver transplant, with or without cirrhosis (Child-Pugh class A, B, or C). All of these patients were randomized to receive either 12 or 24 weeks of LDV/SOF with RBV. SVR 12 rates among patients without cirrhosis and compensated cirrhosis were $96 \%$ and $98 \%$, respectively. These rates were not affected by duration of treatment or cirrhosis status. In patients with ChildPugh class B cirrhosis, the rates of $\mathrm{SVR}_{12}$ were similar with 12 weeks and 24 weeks of treatment ( $86 \%$ vs. $88 \%$ ). Although there were lower $\mathrm{SVR}_{12}$ rates in patients with ChildPugh class $C$ disease ( $60 \%$ after 12 weeks of treatment and $75 \%$ after 24 weeks), this cohort was small $(n=9)$. Of note, 7 patients who had cirrhosis underwent liver transplant ( 4 before the end of treatment and 3 before post-treatment week 12). Six of 7 achieved $S R_{12}$; the seventh died of multiorgan failure and septic shock. Since SVR $\mathrm{R}_{12}$ rates were similar despite duration of treatment (12 vs. 24 weeks) and only $4 \%$ of patients discontinued treatment due to adverse events from treatment drugs, this study led to the recommendation that 12 weeks of LDV/SOF+RBV is sufficient for patients after liver transplant. However, since all patients in the study received $\mathrm{RBV}$, regardless of treatment duration, the role of RBV in higher SVR achievement could not be ascertained definitively from this study.

Second, the observational cohort HCV-TARGET ${ }^{37}$ included 347 patients with liver transplants, 279 of whom received LDV/SOF for 12 or 24 weeks. The SVR 12 rates were $97 \%$
(152/157) for those who received RBV and 95\% (116/122) in the group that did not take RBV. Patients who received RBV were more frequently GT1a, treatment-experienced, and had intact renal function. The rate of therapy discontinuation was only $1.3 \%$. Third, a multicenter cohort ${ }^{38}$ of 162 patients (mostly GT1) assessed response rates of LDV/SOF with or without RBV for 8,12 or 24 weeks. Overall, $94 \%$ and $98 \%$ achieved $S R_{12}$ when receiving LDV/SOF without or with RBV, respectively. The $S R_{12}$ rate among patients who received 8 weeks of treatment was $86 \%$, but did not differ greatly for 12 versus 24 weeks ( $94 \%$ vs. $95 \%$ ). SVR S $_{12}$ rates in the RBV groups for 12 and 24 weeks was $97 \%$ and $100 \%$, respectively. These studies suggest that high rates of SVR can be achieved without RBV; however, the addition of RBV may be considered for patients with an unfavorable baseline profile (i.e. cirrhosis, treatment-experienced).

For patients with GT2 or GT3 infection (with or without HCV treatment experience and/or compensated cirrhosis), the ALLY-1 trial ${ }^{39}$ and that by Fontana et al. ${ }^{40}$ demonstrate that DCV/SOF+RBV for 12 weeks is an effective regimen. In the ALLY-1 trial, ${ }^{39}$ DCV/SOF+RBV was given for 12 weeks to 60 patients, both treatment-naïve and treatment-experienced, with Child-Pugh class A, B, or C cirrhosis after liver transplant. Eleven patients with GT3 were included in the trial; up to $83 \%$ (5/6) with advanced cirrhosis and $91 \%$ (10/11) with recurrent HCV after transplant achieved $S_{12}$. In the study by Fontana et al., ${ }^{40}$ the overall $\mathrm{SVR}_{12}$ rate with DCV/SOF+RBV (for all genotypes) was $91 \%$ (70/77). Only 3 patients had GT2 or GT3, and they all received DCV/SOF+RBV and achieved SVR $\mathrm{S}_{12}$. There have been no studies in patients with decompensated cirrhosis after liver transplant, so the AASLD/IDSA guidelines ${ }^{4}$ recommend using DCV/SOF+RBV for 12 weeks or SOF/VEL with RBV for 12 weeks.

\section{Resource-limited settings}

More than $80 \%$ of the worldwide HCV burden is in low- and middle-income countries; ${ }^{41}$ however, treatment escalation in these areas has been hindered by the high cost of DAAs in developing countries. ${ }^{42} \mathrm{~A}$ study by Iyengar et al. ${ }^{43}$ analyzed and compared prices of DAAs in 30 countries, noting that people in developing countries had more risk of paying higher adjusted prices than people in developed countries. Furthermore, they noted the price of generic SOF was more than the annual earnings for individuals in 12 of the 30 countries they analyzed. The World Health Organization (commonly known as WHO) estimates that in Ukraine, for example, a 4-week course of PEG-IFN $\alpha$ and RBV is $\$ 139$, compared to $\$ 812$ for 4 weeks of LDV/SOF.44 These facts highlight the conundrum that although DAAs are more efficacious and have fewer side effects than PEG-IFN $\alpha$ /RBV regimens, the cost of DAAs remains prohibitive for most patients who need to be treated worldwide. Therefore, in resource-limited settings or countries with a low gross domestic product, RBV (in combination with PEG-IFN $\alpha$ ) may be the only accessible treatment option at present based on cost, particularly for easier to treat genotypes.

\section{Conclusions}

The WHO has established a goal to treat $80 \%$ of those with chronic HCV worldwide by 2030, an aspiration that, with the advent of combination DAA-based regimens, appears within reach for the first time. ${ }^{45}$ With the recent changes in the 
guidelines and use of DAAs in the treatment of $\mathrm{HCV}$, regimens have become more tolerable, effective, and less complicated, enabling HCV to be treated by primary care and midlevel providers, ${ }^{46}$ with minimal laboratory monitoring. Therefore, the use of RBV should be restricted to patients who have failed previous regimens and/or have decompensated cirrhosis, as there is data to support use in these populations. In both instances, as more and more new regimens become available, RBV's utility will need to be revaluated, since RBV use is associated with significant anemia in decompensated patients ${ }^{47}$ and end-stage renal disease, ${ }^{48}$ and retreatment studies are relatively small and restricted to a few regimens. Addition of RBV to all DAA regimens to treat HCV patients is not advisable and may be hazardous. While there may be disagreement about RBV's efficacy and incidence of adverse events in the current era of HCV treatment, ${ }^{49}$ we recommend that the use of RBV should be limited to treatment in complicated patients who are managed under close supervision and should not be used to treat patients in primary care settings with uncomplicated $\mathrm{HCV}$.

\section{Conflict of interest}

The authors have no conflict of interests related to this publication.

\section{Author contributions}

Responsible for drafting the article (PM, EW), involved in the critical revision of the article (EW, SK). All authors reviewed and approved the version of the article submitted.

\section{References}

[1] Global prevalence and genotype distribution of hepatitis $C$ virus infection in 2015: a modelling study. Lancet Gastroenterol Hepatol 2017;2:161-176. doi: 10.1016/S2468-1253(16)30181-9.

[2] Stanaway JD, Flaxman AD, Naghavi M, Fitzmaurice C, Vos T, Abubakar I et al. The global burden of viral hepatitis from 1990 to 2013: findings from the Global Burden of Disease Study 2013. Lancet 2016;388:1081-1088. doi: 10.1016/S0140-6736(16)30579-7.

[3] Vutien $P_{\text {, Jin }} \mathrm{M}$, Le $\mathrm{MH}$, Nguyen $\mathrm{P}$, Trinh $\mathrm{S}$, Huang JF, et al. Regional differences in treatment rates for patients with chronic hepatitis $\mathrm{C}$ infection: Systematic review and meta-analysis. PLoS One 2017;12:e0183851. doi: 10.1371/journal.pone. 0183851.

[4] The American Association for the Study of Liver Diseases and the Infectious Diseases Society of America Present. HCV Guidance: Recommendations for Testing, Managing, and Treating Hepatitis C. Available from: http://www. tasl.org.tr/upload/content/files/hcv-guidance-september-21-2017-d.pdf, accessed September 2017.

[5] Afdhal N, Zeuzem S, Kwo P, Chojkier M, Gitlin N, Puoti M, et al. Ledipasvir and sofosbuvir for untreated HCV genotype 1 infection. N Engl J Med 2014; 370:1889-1898. doi: 10.1056/NEJMoa1402454.

[6] Lawitz E, Poordad FF, Pang PS, Hyland RH, Ding X, Mo H, et al. Sofosbuvir and ledipasvir fixed-dose combination with and without ribavirin in treatmentnaive and previously treated patients with genotype 1 hepatitis $C$ virus infection (LONESTAR): an open-label, randomised, phase 2 trial. Lancet 2014; 383:515-523. doi: 10.1016/S0140-6736(13)62121-2.

[7] Sulkowski MS, Gardiner DF, Rodriguez-Torres M, Reddy KR, Hassanein T, Jacobson I, et al. Daclatasvir plus sofosbuvir for previously treated or untreated chronic HCV infection. N Engl J Med 2014;370:211-221. doi: 10.1056/NEJMoa1306218.

[8] McHutchison JG, Gordon SC, Schiff ER, Shiffman ML, Lee WM, Rustgi VK, et $a l$. Interferon alfa-2b alone or in combination with ribavirin as initial treatment for chronic hepatitis C. Hepatitis Interventional Therapy Group. N Engl J Med 1998;339:1485-1492. doi: 10.1056/NEJM199811193392101.

[9] Testoni B, Levrero M, Durantel D. Mechanism of action of ribavirin in antiHCV regimens: new insights for an age-old question? Gut 2014;63:3-4. doi: $10.1136 /$ gutjnl-2013-304528.
[10] Fried MW, Shiffman ML, Reddy KR, Smith C, Marinos G, Gonçales FL Jr, et al. Peginterferon alfa-2a plus ribavirin for chronic hepatitis $C$ virus infection. N Engl J Med 2002;347:975-982. doi: 10.1056/NEJMoa020047.

[11] Hadziyannis SJ, Sette H Jr, Morgan TR, Balan V, Diago M, Marcellin P, et al. Peginterferon-alpha2a and ribavirin combination therapy in chronic hepatitis $\mathrm{C}$ a randomized study of treatment duration and ribavirin dose. Ann Intern Med 2004;140:346-355. doi: 10.7326/0003-4819-140-5-200403020-00010.

[12] Manns MP, McHutchison JG, Gordon SC, Rustgi VK, Shiffman M, Reindollar R, et $a l$. Peginterferon alfa-2b plus ribavirin compared with interferon alfa-2b plus ribavirin for initial treatment of chronic hepatitis C: a randomised trial. Lancet 2001;358:958-965. doi: 10.1016/S0140-6736(01)06102-5.

[13] Shepherd J, Waugh N, Hewitson P. Combination therapy (interferon alfa and ribavirin) in the treatment of chronic hepatitis $\mathrm{C}$ : a rapid and systematic review. Health Technol Assess 2000;4:1-67.

[14] Di Bisceglie AM, Conjeevaram HS, Fried MW, Sallie R, Park Y, Yurdaydin C, et al. Ribavirin as therapy for chronic hepatitis C. A randomized, double-blind, placebocontrolled trial. Ann Intern Med 1995;123:897-903. doi: 10.7326/0003-4819123-12-199512150-00001.

[15] Russmann S, Grattagliano I, Portincasa P, Palmieri VO, Palasciano G. Ribavirin-induced anemia: mechanisms, risk factors and related targets for future research. Curr Med Chem 2006;13:3351-3357. doi: $10.2174 / 092986706778773059$.

[16] REBETOL ${ }^{\circ}$ (ribavirin USP) capsules, for oral use. Available from: http://www. merck.com/product/usa/pi_circulars/r/rebetol/rebetol_pi.pdf.

[17] Moderiba(R) [package insert]. Abbvie, Inc. North Chicago, IL. Accessed February 2015

[18] Poordad F, McCone J Jr, Bacon BR, Bruno S, Manns MP, Sulkowski MS, et al. Boceprevir for untreated chronic HCV genotype 1 infection. N Engl J Med 2011;364:1195-1206. doi: 10.1056/NEJMoa1010494.

[19] Zeuzem S, Andreone P, Pol S, Lawitz E, Diago M, Roberts S, et al. Telaprevir for retreatment of HCV infection. N Engl J Med 2011;364:2417-2428. doi: $10.1056 /$ NEJMoa1013086.

[20] Kohli A, Shaffer A, Sherman A, Kottilil S. Treatment of hepatitis C: a systematic review. JAMA 2014;312:631-640. doi: 10.1001/jama.2014.7085.

[21] Meissner EG, Nelson A, Marti M, Masur H, Osinusi A, Kottilil S. Sustained virologic response for chronic hepatitis $C$ infection after 27 days of treatment with sofosbuvir and ribavirin. Open Forum Infect Dis 2014;1:013. doi: 10.1093/ofid/ofu013.

[22] Tang L, Ward H, Kattakuzhy S, Wilson E, Kottilil S. Dual sofosbuvir and ribavirin therapy for chronic hepatitis C infection. Expert Rev Gastroenterol Hepatol 2016;10:21-36. doi: 10.1586/17474124.2016.1119042.

[23] Pol S, Ghalib RH, Rustgi VK, Martorell C, Everson GT, Tatum HA, et al. Daclatasvir for previously untreated chronic hepatitis $C$ genotype- 1 infection: a randomised, parallel-group, double-blind, placebo-controlled, dose-finding, phase $2 a$ trial. Lancet Infect Dis 2012;12:671-677. doi: 10.1016/S14733099(12)70138-X

[24] Kowdley KV, Lawitz E, Poordad F, Cohen DE, Nelson DR, Zeuzem S, et al. Phase $2 \mathrm{~b}$ trial of interferon-free therapy for hepatitis $\mathrm{C}$ virus genotype 1 N Engl J Med 2014;370:222-232. doi: 10.1056/NEJMoa1306227.

[25] Suwanthawornkul T, Anothaisintawee T, Sobhonslidsuk A, Thakkinstian A Teerawattananon Y. Efficacy of second generation direct-acting antivira agents for treatment naïve hepatitis C genotype 1: A systematic review and network meta-analysis. PLoS One 2015;10:e0145953. doi: 10. 1371/journal.pone.0145953.

[26] Feld J], Kowdley KV, Coakley E, Sigal S, Nelson DR, Crawford D, et al. Treatment of HCV with ABT-450/r-ombitasvir and dasabuvir with ribavirin. N Eng J Med 2014;370:1594-1603. doi: 10.1056/NEJMoa1315722.

[27] Ferenci P, Bernstein D, Lalezari J, Cohen D, Luo Y, Cooper C, et al. ABT-450/ r-ombitasvir and dasabuvir with or without ribavirin for HCV. N Engl J Med 2014;370:1983-1992. doi: 10.1056/NEJMoa1402338.

[28] Zeuzem S, Jacobson IM, Baykal T, Marinho RT, Poordad F, Bourlière M, et al. Retreatment of $\mathrm{HCV}$ with $\mathrm{ABT}-450 / \mathrm{r}$-ombitasvir and dasabuvir with ribavirin. N Engl J Med 2014;370:1604-1614. doi: 10.1056/NEJMoa1401561.

[29] Zeuzem S, Ghalib R, Reddy KR, Pockros PJ, Ben Ari Z, Zhao Y, et al. Grazoprevirelbasvir combination therapy for treatment-naive cirrhotic and noncirrhotic patients with chronic hepatitis C virus genotype 1, 4, or 6 infection: A randomized trial. Ann Intern Med 2015;163:1-13. doi: 10.7326/M150785 .

[30] Kwo P, Gane EJ, Peng CY, Pearlman B, Vierling JM, Serfaty L, et al. Effectiveness of elbasvir and grazoprevir combination, with or without ribavirin, for treatment-experienced patients with chronic hepatitis $C$ infection. Gastroenterology 2017;152:164-175.e4. doi: 10.1053/j.gastro.2016.09.045.

[31] Forns X, Gordon SC, Zuckerman E, Lawitz E, Calleja JL, Hofer $\mathrm{H}$, et al. Grazoprevir and elbasvir plus ribavirin for chronic HCV genotype-1 infection after failure of combination therapy containing a direct-acting antiviral agent. J Hepatol 2015;63:564-572. doi: 10.1016/j.jhep.2015.04.009.

[32] Bourlière $M$, Bronowicki JP, de Ledinghen $V$, Hézode $C$, Zoulim $F$, Mathurin $P$, et al. Ledipasvir-sofosbuvir with or without ribavirin to treat patients with HCV genotype 1 infection and cirrhosis non-responsive to previous protease-inhibitor therapy: a randomised, double-blind, phase 2 trial 
(SIRIUS). Lancet Infect Dis 2015;15:397-404. doi: 10.1016/S1473-3099 (15)70050-2.

[33] Pianko S, Flamm SL, Shiffman ML, Kumar S, Strasser SI, Dore G], et al. Sofosbuvir plus velpatasvir combination therapy for treatment-experienced patients with genotype 1 or 3 hepatitis $C$ virus infection: A randomized trial. Ann Intern Med 2015;163:809-817. doi: 10.7326/M15-1014.

[34] Hézode C, Asselah T, Reddy KR, Hassanein T, Berenguer M, FleischerStepniewska $\mathrm{K}$, et al. Ombitasvir plus paritaprevir plus ritonavir with or without ribavirin in treatment-naive and treatment-experienced patients with genotype 4 chronic hepatitis $C$ virus infection (PEARL-I): a randomised open-label trial. Lancet 2015;385:2502-2509. doi: 10.1016/S0140-6736 (15)60159-3.

[35] Curry MP, O'Leary JG, Bzowej N, Muir AJ, Korenblat KM, Fenkel JM, et al. Sofosbuvir and velpatasvir for $\mathrm{HCV}$ in patients with decompensated cirrhosis. N Engl J Med 2015;373:2618-2628. doi: 10.1056/NEJMoa1512614.

[36] Charlton M, Everson GT, Flamm SL, Kumar P, Landis C, Brown RS Jr, et al. Ledipasvir and sofosbuvir plus ribavirin for treatment of HCV infection in patients with advanced liver disease. Gastroenterology 2015;149: 649-659. doi: 10.1053/j.gastro.2015.05.010.

[37] Saxena V, Khungar V, Verna EC, Levitsky J, Brown RS Jr, Hassan MA, et al. Safety and efficacy of current direct-acting antiviral regimens in kidney and liver transplant recipients with hepatitis C: Results from the HCV-TARGET study. Hepatology 2017;66:1090-1101. doi: 10.1002/hep.29258.

[38] Kwok RM, Ahn J, Schiano TD, Te HS, Potosky DR, Tierney A, et al. Sofosbuvir plus ledispasvir for recurrent hepatitis $C$ in liver transplant recipients. Liver Transpl 2016;22:1536-1543. doi: 10.1002/It.24614.

[39] Poordad F, Schiff ER, Vierling JM, Landis C, Fontana RJ, Yang R, et al. Daclatasvir with sofosbuvir and ribavirin for hepatitis $C$ virus infection with advanced cirrhosis or post-liver transplantation recurrence. Hepatology 2016;63:1493-1505. doi: 10.1002/hep.28446.

[40] Fontana RJ, Brown RS Jr, Moreno-Zamora A, Prieto M, Joshi S, Londoño MC, et al. Daclatasvir combined with sofosbuvir or simeprevir in liver transplant recipients with severe recurrent hepatitis $C$ infection. Liver Transpl 2016;22: 446-458. doi: 10.1002/lt.24416.

[41] Suthar AB, Harries AD. A public health approach to hepatitis $C$ control in low- and middle-income countries. PLoS Med 2015;12:e1001795. doi: 10.1371/journal. pmed.1001795.

[42] Ford N, Singh K, Cooke GS, Mills EJ, von Schoen-Angerer T, Kamarulzaman $A$, et al. Expanding access to treatment for hepatitis $C$ in resource-limited settings: lessons from HIV/AIDS. Clin Infect Dis 2012;54:1465-1472. doi: $10.1093 / \mathrm{cid} / \mathrm{cis} 227$.
[43] Iyengar S, Tay-Teo K, Vogler S, Beyer P, Wiktor S, de Joncheere $K$, et al. Prices, costs, and affordability of new medicines for hepatitis $C$ in 30 countries: An economic analysis. PLoS Med 2016;13:e1002032. doi: 10.1371/journal. pmed.1002032.

[44] Guidelines for the screening care and treatment of persons with chronic hepatitis C infection: Updated version. Available from: https://www.ncbi.nlm. nih.gov/pubmedhealth/PMH0093400/.

[45] World Health Organization. Combining hepatitis $B$. and $C$ to reach elimination by 2030. Available from: http://www.who.int/hepatitis/publications/hepelimination-by-2030-brief/en/, accessed May 2016.

[46] Kattakuzhy S, Gross C, Emmanuel B, Teferi G, Jenkins V, Silk R, et al. Expansion of treatment for hepatitis $C$ virus infection by task shifting to community-based nonspecialist providers: A nonrandomized clinical trial. Ann Intern Med 2017; 167:311-318. doi: 10.7326/M17-0118.

[47] Danish FA, Koul SS, Subhani FR, Rabbani AE, Yasmin S. Antiviral therapy in HCV-infected decompensated cirrhotics. Saudi J Gastroenterol 2010;16: 310-314. doi: 10.4103/1319-3767.70632.

[48] Romero-Gómez M, Berenguer M, Molina E, Calleja JL. Management of anemia induced by triple therapy in patients with chronic hepatitis C: challenges, opportunities and recommendations. J Hepatol 2013;59:1323-1330. doi: 10.1016/j.jhep.2013.07.014.

[49] Feld J], Jacobson IM, Sulkowski MS, Poordad F, Tatsch F, Pawlotsky JM. Ribavirin revisited in the era of direct-acting antiviral therapy for hepatitis C virus infection. Liver Int 2017;37:5-18. doi: 10.1111/liv.13212.

[50] Lawitz E, Lalezari JP, Hassanein T, Kowdley KV, Poordad FF, Sheikh AM, et al. Sofosbuvir in combination with peginterferon alfa-2a and ribavirin for non-cirrhotic, treatment-naive patients with genotypes 1,2 , and 3 hepatitis C infection: a randomised, double-blind, phase 2 trial. Lancet Infect Dis 2013;13:401-408. doi: 10.1016/S1473-3099(13)70033-1.

[51] Jacobson IM, Gordon SC, Kowdley KV, Yoshida EM, Rodriguez-Torres M, Sulkowski MS, et al. Sofosbuvir for hepatitis C genotype 2 or 3 in patients without treatment options. N Engl J Med 2013;368:1867-1877. doi: 10.1056/ NEJMoa1214854.

[52] Kowdley KV, Lawitz E, Crespo I, Hassanein T, Davis MN, DeMicco M, et al. Sofosbuvir with pegylated interferon alfa-2a and ribavirin for treatmentnaive patients with hepatitis C genotype- 1 infection (ATOMIC): an openlabel, randomised, multicentre phase 2 trial. Lancet 2013;381:2100-2107. doi: 10.1016/S0140-6736(13)60247-0.

[53] Osinusi A, Meissner EG, Lee Y], Bon D, Heytens L, Nelson A, et al. Sofosbuvir and ribavirin for hepatitis $C$ genotype 1 in patients with unfavorable treatment characteristics: a randomized clinical trial. JAMA 2013;310:804-811. doi: 10.1001/jama.2013.109309. 